\section{Influence of Different Coronal Preflaring Protocols on Electronic Foramen Locators Precision}

Andrélia Maciel Melo ${ }^{10}$, Nilton Vivacqua-Gomes ${ }^{10}$, Ricardo Affonso Bernardes $^{2}$, Rodrigo Ricci Vivan ${ }^{3}$, Marco Antônio Húngaro Duarte ${ }^{3}$, Bruno Carvalho de Vasconcelos ${ }^{4}$

The aim of this study was to evaluate the influence of different coronal preflaring protocols (absent, conservative and conventional) on the accuracy of Root ZX II, Raypex 6 , and RomiApex A-15 electronic foramen locators (EFLs). Twenty mandibular molars with Vertucci's type IV mesial roots were subjected to endodontic exploration and foraminal patency confirmation. Under $16 x$ magnification, its real lengths $(\mathrm{RL})$ were measured and registered (RL1). The canals were then irrigated with $2.5 \%$ sodium hypochlorite and electronically measured (EM1) employing the alginate model; all measurements were performed in triplicate by a blind operator using adjusted endodontic hand-files introduced until the apex foramen. Coronal preflaring procedures were sequentially performed with \#25/.06 (conservative) and \#25/.12 (conventional) instruments; new RLs extents were performed after each coronal preparation protocol (RL2/RL3), as same as electronic measurements (EM2/EM3). The devices error ( $\mathrm{mm}$ ) was evaluated considering the difference between RLs and EMs at each preparation stage; their precision was stablished adopting $\pm 0.5 \mathrm{~mm}$ as tolerance margin. The EFLs error significantly reduced after conventional coronal preflaring protocol $(p<0.05)$, which not occur after the conservative one. The best precisions values were noted after conventional preparation as 90\% (Root ZX II), 97.5\% (Raypex 6), and 92.5\% (RomiApex A-15). No significant differences were found in EFLs comparisons, regardless of the coronal protocol tested $(p>0.05)$. Under the conditions tested it can be concluded that the EFLs evaluated were precise. Moreover, the preflaring protocols influences its accuracy's, where the less conservative one produced the best results.

\author{
'School of Dentistry of Ceará, \\ Faculdade São Leopoldo \\ Mandic, Fortaleza, CE, Brazil \\ ${ }^{2}$ Brazilian Dental Association, \\ Taguatinga, DF, Brazil \\ ${ }^{3}$ Department of Dentistry, Endodontics \\ and Dental Materials, Bauru Dental \\ School, USP - Universidade de \\ São Paulo, Bauru, SP, Brazil \\ ${ }^{4}$ Post-graduate Program in Dentistry, \\ UFC - Universidade Federal do \\ Ceará, Fortaleza, CE, Brazil
}

Correspondence: Bruno Carvalho de Vasconcelos, DDS, MSc, PhD, Rua Monsenhor Furtado, 1253, 60430-355 Fortaleza, CE, Brasil. Tel: +55-853366-84-04.e-mail: bcv@ufc.br

Key Words: endodontics, clinical protocols, coronal preparation, electronic foramen locators.

\section{Introduction}

The correct measurement of the apical limits, until which the root canal must be cleaned, is an important key for the success of the endodontic treatment $(1,2)$. Radiographies and electronic foramen locators (EFLs) are the most used methods for measuring the working length of the root canal. Even considering the importance of the radiograph to perform the root canal length measurement, such examination does not ensure precision on the extent of the apical instrumentation limits. Such limitation leads to the necessity of using electronic root canal measurements methods, which are much more precise (3-6) and even more necessary in a clinical context.

Among foramen locators, Root ZX II (J. Morita, Tokyo, Japan) has received special attention due to its outstanding results, which makes such device a standard for comparison (6-10). Root ZX II operates an impedance frequencydependent method based on the quotient of impedance measured in each one of the frequencies in which the device works ( 0.4 and $8 \mathrm{kHz}$ ) (11). The mechanism of interpretation of the impedance at each frequency is what differs one foramen locator from another. Raypex 6 (VDW $\mathrm{GmbH}$, Munich, Germany) and RomiApex A-15 (Romidan Ltd, Kiryat Ono, Israel), for instance, also base their length measurements on impedance at two frequencies, but the mechanism of interpretation of the results they show is different. Both of them exhibit the values of the impedance root square at frequencies 0.4 and $8 \mathrm{kHz}$ for Raypex 6 (VDW $\mathrm{GmbH}$, Munich, Germany) and 0.5 and $8 \mathrm{kHz}$ for RomiApex A-15 (Romidan Ltd, Kiryat Ono, Israel) $(4,9)$.

Investigations have indicated that the precision of the foramen locators might be influenced by clinical situations such as foraminal obstruction (6), apical limit of penetration $(4,9)$, instrument adaptation to the root canal (12-14), and previous coronal preflaring (13-15). The last condition might facilitate the insertion of endodontic files in the coronal portion, leading to a better adaptation of the instrument at the apical third $(15,16)$. Although, the coronal preflaring protocols have been reassessed, some authors have suggested that such procedures might weak the teeth, leaving it more susceptible to root fractures $(17,18)$, suggesting that the coronal preparation has to be 
cautiously performed or even avoided.

Considering the exposed, this study aims to evaluate the precision of foramen locators Root ZX II, Raypex 6, and RomiApex A-15 after different protocols of coronal preflaring: absent, conservative (\#25/.06), and conventional (\#25/.12). The null hypothesis tested were that 1) different coronal enlargement protocols would not influence the EFLs precisions; 2) no difference would be observed between the EFLs tested.

\section{Material and Methods}

The sample size was calculated based on the study of Camargo et al. (14), using the software $G$ * Power v3.1 (Heinrich Heine, Universität Düsseldorf, Düsseldorf, Germany), adopting an a of $5 \%$, a beta potency of 0.8 , and a N2/N1 ratio of 1, and considering the test Wilcoxon-Mann Whitney. The calculation revealed the need for 32 root canals, but the sample size was extended to 40 dues to the possibility of losses during the mechanical instrumentation.

Thus, after approval by the local Ethics Committee (protocol \#2.913.361/2018), 20 mandibular molars presenting Vertucci type IV mesial roots without pronounced dilacerations $\left(<25^{\circ}\right)$, with apical patency and an apical foramen $\leq 200 \mu \mathrm{m}$ were included in this investigation; digital periapical radiographs and clinical observations were employed. Teeth that did not fulfill these requirements or that presented any sign of root resorption were replaced.

The access cavity was performed using diamond drills \#1013 and \#3081 (KG Sorensen, Cotia, SP, Brazil) under high speed rotation and abundant irrigation. The cusps tips were flattened using \#3081 diamond drill in order to standardize the measurement of the real length of the root canal (RL). C-Pilot \#08, \# 10, \#15 (VDW GmbH) and Nitiflex \#20 hand-files (Dentsply-Sirona, Ballaigues, Switzerland) were inserted into the canals until their tips could be seen through the apical foramen under a 16x magnification of a clinical microscope (Alliance, São Carlos, SP, Brazil). The hand NiTi file that better adapt to the apical foramen was registered as initial file and the silicone stop was stabilized at the occlusal board of the tooth; this record made it possible to assess adapted file size alteration. Then, the file was removed and its length measured with a digital caliper $(0.001 \mathrm{~mm}$ ) (Mitutoyo, Suzano, SP, Brazil). Such measures were performed in triplicate, and from their results was obtained the means of the reals length, which was considered the initial real length (RL1).

Sequentially, the electronic measurements were performed $(E M 1=$ no coronal preflaring $)$ by an experienced blinded operator using the alginate model; teeth had their root apical thirds inserted in a plastic recipient containing recently manipulated alginate (Jeltrate II; Dentsply Ind. e
Com. Ltda, Petrópolis, Brazil). A lip clip was also inserted in the same recipient, and the measurements were performed while the alginate was still fresh $(<30 \mathrm{~min})$. Before the electronic measurement, the root canals were irrigated with $2.5 \%$ sodium hypochlorite (Biodinâmica, Ibiporã, PR, Brazil) which excess was removed through aspiration. The measurements were performed inserting hand NiTi-files until the devices indicated the apical foramen $(0.0 \mathrm{~mm})$; the measurements (length and size) were registered only with adapted files. Such procedure was repeated three times alternating the order of foramen locators employment; the 40 root canals were electronically measured by the three EFLs $(n=40)$.

\section{Data Collection after Coronal Preflaring}

Coronal and middle thirds were prepared with \#25/.06 (conservative preflaring) instruments (Prodesign Logic; Bassi Endo Product, Belo Horizonte, MG, Brazil) driven by the VDW Silver motor (VDW GmbH) at 600 RPM and 300 g.cm employing forward rotation kinematics. After this conservative preflaring protocol accomplishment root canal length (RL2) and electronic measurements (EM2) were once again performed. Sequentially, \#25/.12 (conventional preflaring) instruments (HyFlex EDM; Coltene-Whaledent, Allstätten, Switzerland) were driven at 350 RPM and 300 g.cm employing forward rotation kinematics. At the end of conventional coronal enlargement procedures the root canals length was over again manually (RL3) and electronically (EM3) measured as previously described. Regardless of the instrument used, for each three forward and backward movement, the root canals received irrigation with $2.5 \%$ sodium hypochlorite solution.

The foramen locator's accuracies were determined by calculating the difference between the means of the electronic measurement triplicates compared to the manual measures of canals real length at each phase pf preflaring preparation (RL1 vsEM1; RL2 vs EM2; and RL3 vs EM3). This comparison allowed the calculation of the mean error of the devices on the measurement of the root canal length. The percentage of devices precision was established considering a maximum variation of $\pm 0.5 \mathrm{~mm}$.

\section{Statistical Analysis}

The data was analyzed by Shapiro-Wilk test that pointed its normal distribution. Then, the values were analyzed by ANOVA test followed by Tukey's test, both with a significance level set at $5 \%$.

\section{Results}

The data of root canal length according to coronal preflaring and EFL are depicted in Table 1. It can be seen that no significant differences were found when comparing 
the devices tested according to coronal preflaring protocol. However, for all devices, differences among their mean errors after conventional coronal preflaring with \#25/.12 instrument and without any coronal preparation were observed $(p<0.05)$. On the other hand, when comparing the conservative and conventional preflaring protocols no significant differences were found.

Table 2 presents the distribution of the percentage of precision of the devices tested. These data reveal that the accuracy was increased after the coronal preflaring. Considering a tolerance margin of $\pm 0.5 \mathrm{~mm}$, the precision of all the devices tested without preflaring was 67.5\%; higher precision values were observed after conventional coronal preflaring with $97.5 \%$ for Raypex 6, 92.5\% for RomiApex A-15, and 90\% for Root ZX II.

Considering the methods performed an additional observation could be done regarding the apical file adjustment. After preflaring protocols a total of $72.5 \%$ of root canals increased their initial file size, $32.5 \%$ after conservative coronal enlargement (\#25/.06) and 42.5\% after the conventional protocol (\#25/.12); just one root

\begin{tabular}{|c|c|c|c|c|c|c|}
\hline \multirow[b]{2}{*}{ Device } & \multicolumn{2}{|c|}{ Unflared } & \multicolumn{2}{|l|}{$\# 25 / .06$} & \multicolumn{2}{|c|}{$\# 25 / .12$} \\
\hline & Mean* & sd & Mean* & sd & Mean* & sd \\
\hline Root ZX II & $0.38^{\mathrm{a}, \mathrm{B}}$ & 0.23 & $0.31^{\mathrm{a}, \mathrm{AB}}$ & 0.23 & $0.26^{\mathrm{a}, \mathrm{A}}$ & 0.19 \\
\hline Raypex 6 & $0.38^{\mathrm{a}, \mathrm{B}}$ & 0.26 & $0.33^{\mathrm{a}, \mathrm{AB}}$ & 0.24 & $0.21^{\mathrm{a}, \mathrm{A}}$ & 0.20 \\
\hline Propex Pixi & $0.41^{\mathrm{a}, \mathrm{B}}$ & 0.26 & $0.33^{\mathrm{a}, \mathrm{AB}}$ & 0.23 & $0.26^{\mathrm{a}, \mathrm{A}}$ & 0.20 \\
\hline
\end{tabular}

*Mean error calculated in terms of absolute values of the determinations. ${ }^{\mathrm{a}, \mathrm{b}} \mathrm{Different}$ superscript lower case letters indicate statistically significant differences between devices considering each condition according to ANOVA and Tukey tests $(\mathrm{p}<0.05)$. canal increased after both protocols.

\section{Discussion}

The role of the coronal preflaring on the cleaning and widening of the root canal to create a more favorable pathway for the preparation of root canal apical third is already known $(16,19,20)$. Coronal preflaring is recognized to positively influence the precision of foramen locators (13-15), however, Vasconcelos et al. (7) did not observe accuracy improvement for the use of the Root ZX II foramen locator when coronal preflaring of the root canals was employed. Such result may differ from what the literature has reported since a more conservative approach of coronal preflaring was used. To the best of our knowledge, there was no study evaluating the influence of different patterns of coronal preflaring on the precision of foramen locators. The results found show that conventional preflaring favored the precision of EFLs, regardless of their functioning mechanism. Thus, the first null hypothesis was denied since the coronal enlargement influenced the EFLs precision.

Regarding the methods employed, the mesial root of mandibular molars was elected once these teeth is largely subjected to endodontic treatments $(6,13)$. Moreover, mandibular molars commonly present dentin projections at the coronal thirds of their roots, which hinders the access to the apical third of the root canal, explaining why they were for this evaluation type (21). Even considering the consistency of the literature that underlies the methods used in the present study $(6,7,9,11,14,24)$ must not forget that it is an ex vivo study. Furthermore, despite the care taken to eliminate bias, one cannot fail to consider the necessity to adopt a margin of tolerance for determining the accuracy rate.

ProDesing Logic \#25/.06 and Hyflex EDM \#25/.12 were adopted for conservative and conventional coronal preflaring procedures, respectively. Such instruments were

Table 2. File tip position relative to the apical foramen for measurements performed to 0.0

\begin{tabular}{|c|c|c|c|c|c|c|c|c|c|c|c|c|c|c|c|c|c|c|}
\hline \multirow[b]{3}{*}{$\begin{array}{l}\text { Distance } \\
\text { from AF }\end{array}$} & \multicolumn{6}{|c|}{ Initial } & \multicolumn{6}{|c|}{ \#25/.06 } & \multicolumn{6}{|c|}{$\# 25 / .12$} \\
\hline & \multicolumn{2}{|c|}{ Root ZX II } & \multicolumn{2}{|c|}{ Raypex 6} & \multicolumn{2}{|c|}{$\begin{array}{c}\text { RomiApex } \\
\text { A-15 }\end{array}$} & \multicolumn{2}{|c|}{$\begin{array}{c}\text { Root ZX } \\
\text { II }\end{array}$} & \multicolumn{2}{|c|}{ Raypex 6} & \multicolumn{2}{|c|}{$\begin{array}{c}\text { RomiApex } \\
\text { A-15 }\end{array}$} & \multicolumn{2}{|c|}{$\begin{array}{c}\text { Root ZX } \\
\text { II }\end{array}$} & \multicolumn{2}{|c|}{ Raypex 6} & \multicolumn{2}{|c|}{$\begin{array}{c}\text { RomiApex } \\
\text { A-15 }\end{array}$} \\
\hline & $\mathrm{n}$ & $\%$ & $\mathrm{n}$ & $\%$ & $\mathrm{n}$ & $\%$ & $\mathrm{n}$ & $\%$ & $\mathrm{n}$ & $\%$ & $\mathrm{n}$ & $\%$ & $\mathrm{n}$ & $\%$ & $\mathrm{n}$ & $\%$ & $\mathrm{n}$ & $\%$ \\
\hline$<-0.51^{*}$ & 7 & 17.5 & 9 & 22.5 & 9 & 22.5 & 0 & 0 & 3 & 7.5 & 0 & 0 & 0 & 0 & 0 & 0 & 1 & 2.5 \\
\hline $\begin{array}{l}-0.50 \text { to } \\
-0.01^{*}\end{array}$ & 18 & 45 & 17 & 42.5 & 17 & 42.5 & 16 & 40 & 13 & 32.5 & 13 & 32.5 & 14 & 35 & 16 & 40 & 9 & 22.5 \\
\hline 0.00 & 1 & 2.5 & 0 & 0 & 0 & 0 & 0 & 0 & 0 & 0 & 0 & 0 & 0 & 0 & 0 & 0 & 0 & 0 \\
\hline $\begin{array}{l}0.01 \text { to } \\
0.50\end{array}$ & 8 & 20 & 10 & 25 & 10 & 25 & 16 & 40 & 17 & 42.5 & 20 & 50 & 22 & 55 & 23 & 57.5 & 28 & 70 \\
\hline$>0.51$ & 6 & 15 & 4 & 10 & 4 & 10 & 8 & 20 & 7 & 17.5 & 7 & 17.5 & 4 & 10 & 1 & 2.5 & 2 & 5 \\
\hline
\end{tabular}


chosen due to their recognized capacity of controlled and safe dentin wear $(22,23)$. Alginate was the electroconductive material chosen since it is easily manipulated, presents a low cost, and good reliability $(7,9,14,24)$. The endodontic files used for the electronic measurement had to anatomically fit the apex foramen, which was a reproduction of the methods employed in previous studies $(4,6,9)$.

The present results demonstrated that the foramen locators tested presented satisfactory precision rates even without the coronal preflaring. When a conservative preflaring was performed with instrument \#25/.06 the precision of the devices does not present a significant increase. Differently, when a conventional coronal preparation was employed, i.e. using a \#25/.12 file, the precision of foramen locators significantly increased compared to the condition with-out preflaring: Root ZX II (0.26 mm e 90\%), Raypex 6 (0.21 mm e 97.5\%) and RomiApex A-15 (0.26 mm e 92.5\%). No differences among the devices tested were observed confirming the second null hypothesis. Regarding precision, our results are in agreement with what was found by Vasconcelos et al. (6), who evaluated three devices, including the Root ZX, which observed mean errors and precision that ranged from 0.23 to $0.25 \mathrm{~mm}$ and 93 to $94.75 \%$, respectively. Such results make it possible to suggest that with coronal preflaring, the hand-files used to perform the electronic measurements were better adapted to the apical portion of the root canal, favoring the interpretation of the capacitive and resistive factors related to the impedance of the foramen locators (25). The additional information regarding the adjusted file size increase after the coronal enlargement protocols observed here seems to corroborate this idea. This file anatomical adjustment to the apical foramen has been pointed as a relevant criterion on the precision of foramen locators $(12,13)$.

Regarding the apical file determination, must be considered that the large number of measurements may cause some distortion in the morphology of the root canal apical third, influencing the results as same as anatomical variations related to the occurrence of coronary dentin projections. These limitations could be considered; however, it was precisely because of these factors that hand NiTi files were used and the sample expanded reinforcing the validity of the observed results.

Considering the exposed, the results support that even considering that conservative wear of the coronal dentin should be encouraged, when coronal preflaring is not performed, the precision of the foramen locators might be negatively affected. Moreover, when conventional preflaring protocol was employed higher precision values were reached. Therefore, attention must be paid to the dental anatomy, focusing on the performance of a coronal preflaring with appropriate amplitude, considering all clinical aspects of the endodontic treatment, including the root canal length measurement.

Under the conditions tested it can be concluded that the devices evaluated demonstrated appropriate precision without significant differences. Moreover, an improvement in the accuracy of these devices was observed after conventional coronal preflaring enlargement.

\section{Resumo}

0 objetivo deste estudo foi avaliar a influência de diferentes protocolos de pré-alargamento cervical (ausente, conservador e convencional) na precisão dos localizadores eletrônicos foraminais (LEFs) Root ZX II, Raypex 6 e RomiApex A-15. Vinte molares inferiores com raizes mesiais do tipo IV de Vertucci foram submetidos à exploração endodôntica e confirmação da patência foraminal. Sob ampliação de 16x, seus comprimentos reais (CR) foram medidos e registrados (CR1). Os canais foram então irrigados com hipoclorito de sódio a 2,5\% e medidos eletronicamente (ME1) utilizando o modelo em alginato; todas as medidas foram realizadas em triplicata por um operador cego, utilizando limas endodônticas ajustadas introduzidas até o forame apical. Os procedimentos de pré-alargamento cervical foram realizados sequencialmente com os instrumentos \#25/.06 (conservador) e \#25/.12 (convencional); novas determinações de CRs foram realizadas após cada protocolo de preparação cervical (CR2/CR3), da mesma forma que as medidas eletrônicas (ME2/ME3). 0 erro dos dispositivos ( $\mathrm{mm}$ ) foi avaliado considerando a diferença entre CRs e MEs em cada estágio de preparação; sua precisão foi estabelecida adotando $\pm 0,5 \mathrm{~mm}$ como margem de tolerância. 0 erro dos LEFs reduziu significativamente após o protocolo convencional de alargamento cervical $(p<0,05)$, o que não ocorreu após o conservador. Os melhores valores de precisão foram observados após a preparação convencional como 90\% (Root ZX II), 97,5\% (Raypex 6) e 92,5\% (RomiApex A-15). Não foram encontradas diferenças significantes nas comparações entre os LEFs, independentemente do protocolo cervical testado $(p>0,05)$. Sob as condições testadas, pode-se concluir que os LEFs avaliados foram precisos. Além disso, os protocolos de alargamento influenciam sua precisão, onde o menos conservador produziu os melhores resultados.

\section{References}

1. Riccuci $D$, Langeland K. Apical limit of root canal instrumentation and obturation, part 2: histological study. Int Endod J 1998;31:394-409.

2. Ponce EH, Vilar Fernandez JA. The cemento-dentino-canal junction, the apical foramen and the apical constriction: evaluation by optical microscopy. J Endod 2003;29:214-219.

3. Ravanshad S, Adl A, Anvar J. Effect of working length measurement by electronic foramen locator or radiography on the adequacy of final working length: a randomized clinical trial. J Endod 2010;36:17531756.

4. Vasconcelos BC, Bueno MM, Luna-Cruz SM, Duarte MAH, Fernandes CAO. Accuracy of five electronic foramen locators with different operating systems: an ex vivo study. J Appl Oral Sci 2013;21:132-137.

5. Tsesis I, Blazer T, Ben-Izhack G, Taschieri S, Del Fabro M, Corbella $\mathrm{S}$, et al. The precision of electronic apex locators in working length determination: a systematic review and meta-analysis of the literature. J Endod 2015;41:1818-1823.

6. Vasconcelos BC, Verissimo-Chavez RD, Vivacqua-Gomes N, Candeiro GT, Bernardes RA, Vivan RR, et al. Ex vivo evaluation of the accuracy of electronic foramen locators in root canals with an obstructed apical foramen. J Endod 2015;41:1551-1554.

7. Vasconcelos BC, Bastos LM, Oliveira AS, Bernardes RA, Duarte MAH, Vivacqua-Gomes $N$, et al. Changes in root canal length determined during mechanical preparation stages and their relationship with the accuracy of Root ZX II. J Endod 2016;42:1683-1686.

8. Marigo L, Gervasi L, Somma F, Squeo G, Castagnola F. Comparison of 
two electronic foramen locators on human cadavers. Clin Oral Invest 2016;20:1547-1550.

9. Oliveira TN, Vivacqua-Gomes N, Bernardes RA, Vivan RR, Duarte MAH, Vasconcelos BC. Determination of the accuracy of 5 electronic Foramen locators in the function of different employment protocols. J Endod 2017:43:1663-1667.

10. Goes Cruz AT, Wichnieski C, Carneiro E, da Silva Neto UX, Gambarini G, Piasecki L. Accuracy of 2 Endodontic Rotary Motors with Integrated Foramen locator. J Endod 2017;43:1716-1719.

11. Altunbas $D_{\text {s }}$ Kustarc $A$, Toyoglu $M$. The Influence of various irrigants on the accuracy of 2 electronic foramen locators in locating simulated root perforations. J Endod 2017;43:439-442.

12. Vasconcelos BC, Matos LA, Pinheiro-Júnior EC, Menezes AST, VivacquaGomes N. Ex vivo accuracy of three electronic foramen locators using different apical file sizes. Braz Dent J 2012;23:199-204.

13. Ibarrola JL, Chapman BL, Howard JH, Knowles KI, Ludlow MO. Effect of preflaring on Root ZX foramen locators. J Endod 1999;25:625-626.

14. Camargo EJ, Zapata RO, Medeiros PL, Bramante CM, Bernardineli N, Garcia RB, et al. Influence of preflaring of the accuracy of length determination with four electronic Foramen locators. J Endod 2009;35:1300-1302.

15. Brito-Júnior M, Camilo CC, Moreira-Júnior G, Pécora JD, Sousa-neto MD. Effect of preflaring and file size on the accuracy of two electronic foramen locators. J Appl Oral Sci 2012;20:538-543.

16. Ibelli GS, Barroso JM, Capelli A, Spanó JC, Pécora JD. Influence of cervical preflaring on apical file size determination in maxillary lateral incisors. Braz Dent J 2007;18:102-106.

17. Yuan K, Niu C, Xie Q, Jiang W, Gao L, Huang Z. Comparative evaluation of the impact of minimally invasive preparation vs. conventional straight-line preparation on tooth biomechanics: a finite element analysis. Eur J Oral Sci 2016;124:591-596.
18. Krishan R, Paqué F, Ossareh A, Kishen A, Dao T, Friedman s. Impacts of conservative endodontic cavity on root canal instrumentation efficacy and resistance to fracture assessed in incisors, premolars, and molars. J Endod 2014;40:1160-1166.

19. Vanni JR, Santos R, Limongi O, Guerisoli DM, Capeli A, Pécora JD. Influence of cervical preflaring on determination of apical file size in maxillary molars: SEM analysis. Braz Dent J 2005;16:181-186.

20. Borges $A H$, Pereira TM, Porto AN, de Araújo Estrela $C R$, de Miranda Pedro FL, Aranha AM. The influence of cervical preflaring on the amount of apically extruded debris after root canal preparation using different instrumentation systems. J Endod 2016;42:465-469.

21. Oliveira MA, Venâncio JF, Raposo LH, Barbosa Júnior $N$, Biffi JC. Morphometric evaluation and planning of anticurvature filing in roots of maxillary and mandibular molars. Braz Oral Res 2015;29:1-9.

22. Pirani C, lacono F, Generali L, Sassatelli P, Nucci C, Lusvarghi L. Hyflex EDM: superficial features, metallurgical analysis and fatigue resistance of innovative electro discharge machined NiTi Rotary instruments. Int Endod J 2016;49:483-493.

23. Pinheiro SR, Alcalde MP, Vivacqua-Gomes N, Bramante CM, Vivan RR, Duarte MAH. Evaluation of apical transportation and centring ability of five thermally treated NiTi rotary systems. Int Endod J 2018;51:705713.

24. Baldi JV, Victorino FR, Bernardes RA, de Moraes IG, Bramante CM, Garcia RB. Influence of embedding media on the assessment of electronic. foramen locators. J Endod 2007;33:476-479.

25. Nekoofar MH, Ghandi MM, Hayes SJ, Dummer PMH. The fundamental operating principles of electronic root canal length measurement devices. Int Endod J 2006;39:595-609.

Received March 25, 2020

Accepted May 4, 2020 